\title{
Continuity in Morality and Law
}

\author{
Re'em Segev*
}

\begin{abstract}
According to the an influential and intuitively appealing argument (the Continuity Argument): (1) morality is usually continuous, namely, a gradual change in one morally significant factor triggers a gradual change in another; (2) the law should usually track morality; (3) therefore, the law should often be continuous. This argument is illustrated by cases such as the following example: since the moral difference between a defensive action that is reasonable and one that is just short of being reasonable is small, the law should not impose a severe punishment when the action is almost reasonable and no punishment at all when action is reasonable (as positive law sometimes does). In this paper, I consider two doubts regarding this argument. First, the premise that morality is continuous in such cases is incompatible with the common view that the moral status of actions is not continuous since there is an important difference between actions that are permissible and actions that are wrong - even if this difference is due to a difference that is very small, such as the one between an action whose consequences are the best and an action whose consequences are just slightly less good. This view extends also to the overall moral status of agents given the common assumption that it depends on the moral status of their actions. This is an important challenge that the Continuity Argument should confront. However, I argue that
\end{abstract}

${ }^{*}$ Faculty of Law, the Hebrew University of Jerusalem. I am grateful to Adam Kolber, Shahar Eldar, Ofer Malcai, Omer Pelled, Dana Gur, Amihai Wasserteil, and the participants in the Conference on Legal Discontinuity at Tel-Aviv University for helpful comments; to Inbar Gil for excellent research assistance; and to the Israel Science Foundation for financial support (Grant 888/18). 
the best account of morality is more scalar than the common view in these respects. Therefore, I conclude that the first premise of the Continuity Argument is correct in this regard, although it is based on a minority view. The second doubt concerns the scope of the second premise: since there are both reasons in favor and reasons against legal continuity, and the applicability and force of these reasons depend not only on various moral propositions but also on contingent non-moral facts, we lack the evidence to determine the degree to which the law, at a certain place and time, should be continuous and specifically that it should be often continuous.

\section{Table of Contents}

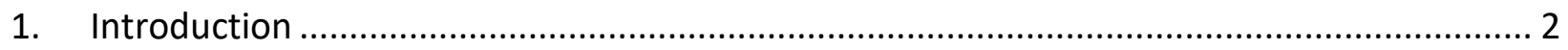

2. The First Premise: Scalar Morality .......................................................................... 10

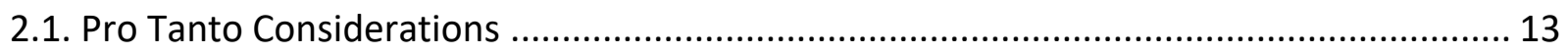

2.2. The Overall Moral Status of Actions \& Agents ............................................................ 18

3. The Second Premise: The Morality of Law .................................................................... 30

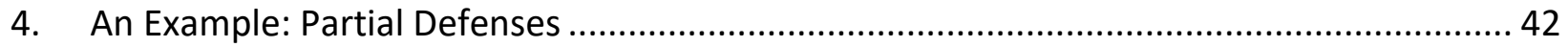

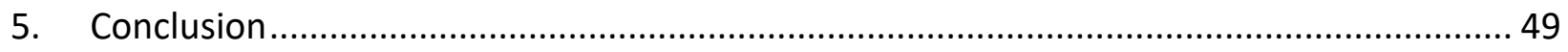

\section{Introduction}

Consider the following argument (the Continuity Argument) regarding morality, the law, and the relation between them:

1. Morality is usually continuous.

2. The law should usually track morality.

3. Therefore, the law should often be continuous.

The conclusion of the Continuity Argument is the basis of an auxiliary argument concerning positive law (which is similar, in the relevant respects, in many countries):

3. The law should often be continuous (the conclusion of the Continuity Argument).

4. The law is often discontinuous.

5. Therefore, the law should be amended so that it is often continuous. 
The Continuity Argument is appealing and influential. Indeed, it is supported by people whose normative outlooks are very different. For example, one common version of this argument assumes a deontological theory that emphasizes the importance of desert and accordingly condemns criminal punishment that exceeds the degree to which the agent is blameworthy. ${ }^{1}$ In contrast, the Continuity Argument was promoted more generally by Adam Kolber who espouses a consequentialist position that rejects desert. ${ }^{2}$

The Continuity Argument focuses especially on the part of morality that is concerned with the overall moral status of actions - whether they are obligatory, permissible or wrong (for example) - and the overall moral status of agents - whether they are (more or less) praiseworthy or blameworthy. The sense of continuity that is employed in this argument is that a gradual change in one morally significant factor - such as the degree to which an action is wrong or an agent is blameworthy - triggers a gradual change in another factor that is morally significant - for example, the appropriate legal sanction. Kolber illustrates the argument (inter alia) with the examples that focus on the overall moral status of actions and agents. One example concerns the criminal law: he argues that since the moral difference between a defensive action that is reasonable and one that is just short of being reasonable is small, the law should not impose a severe punishment on the agent whose action was almost reasonable, compared to no

${ }^{1}$ See, for example, Husak 2008: 14.

${ }^{2}$ See Kolber 2014: 683; Kolber 2016: 858 ("the criminal law is likely bumpier than necessary"), Kolber 2016: 862 ("I have argued that our leading moral justifications for punishment generally call for smooth relationships between legal inputs and outputs. Yet I will show that the criminal law is frequently bumpy"); Kolber 2016A: 294 ("Morality is usually smooth, but the law is usually bumpy... we can often make the law smoother, and we should when bumpy laws come at too high of a moral cost"), Kolber 2016A: 280 ("The set of situations requiring bumpy solutions - cases having what I call 'bumpy needs' - may be relatively small"). 
punishment at all in the case of the reasonable action (as positive law sometimes does). ${ }^{3}$ Another common example concerns tort law: since the moral difference between driving in a way that is completely reasonable and driving in a way that is just slightly unreasonable is small, the law should not require the almost reasonable driver to pay millions in compensation if her action caused a serious accident, compared to nothing at all in the case of a completely reasonable driver who caused a similar accident. ${ }^{4}$

Is the Continuity Argument sound? The argument is valid: assuming plausible senses of "usually" and "often", the conclusion follows from the premises (for example, if "usually" is understood as $80 \%$ and "often" as $64 \%) .{ }^{5}$ However, there are doubts regarding each of the two premises of the argument.

The first doubt concerns the first premise that morality is usually continuous, and specifically that the part of morality that is concerned with the overall moral status of actions and agents is continuous. This proposition is incompatible with the common view that the overall moral status of actions and agents is discontinuous in an important respect, since there is an important difference between actions that are right - obligatory or at least permissible - and actions that are wrong: between what we should do and what we should not do. This is the case, according to this view, even if the difference between actions that are right and actions that are wrong is due to a difference that is very small, such as the difference between an action whose

\footnotetext{
${ }^{3}$ Kolber 2016: 856. Indeed, it seems that, Kolber thinks that the part of morality that is relevant to the criminal law (which includes, he assumes, considerations of retribution, which are concerned with the degree to which the agent is blameworthy, and considerations relating to the degree to which the agent is "dangerous") is completely (and not only usually) continuous.

${ }^{4}$ Kolber 2016A: 279.

${ }^{5}$ My discussion does not depend on the exact way in which these terms are understood.
} 
consequences are the best and an action whose consequences are just slightly less good (very close to being the best). Indeed, according to this view, even if all of the pro tanto moral factors that affect the moral status of actions and agents are continuous, the overall conclusions that are entailed by these factors - regarding the overall moral status of actions and agents - are not continuous.

This is the case most obviously given the standard, maximizing, version of consequentialism, according to which the action whose overall consequences are the best is always obligatory, whereas any other action, including an action whose overall consequences are just slightly less than the best, is wrong. For example, utilitarianism classifies the action that produces the highest sum of well-being as obligatory, and the action that produces just slightly less well-being as wrong. Similarly, a theory that incorporates just one consideration of (moral) desert, classifies the action that brings about the best possible correspondence between virtue and well-being as obligatory and an action that produces just slightly less correspondence between virtue and wellbeing as wrong. The same is true for a more complex consequentialist theory that includes several considerations, for example, in favor of maximizing well-being while giving priority for the worse-off and for the more morally deserving (in accordance with the degree to which they are worse-off or deserving, respectively). Such a theory classifies the action that brings about the best overall consequences in terms of the balance of these factors as a duty and an action that is almost as good as wrong.

This die fact that prominent consequentialist theories are incompatible with the first premise of the Continuity Argument is especially noteworthy since the Continuity Argument is more appealing, to begin with, with respect to consequentialist theories, due to the fact that moral factors that relate to consequences are generally more continuous than deontological ones. However, the Continuity Argument is also incompatible with standard deontological theories for two reasons. First, common deontological constraints - such as a constraint on harming people intentionally - are discontinuous to begin with. Second, standard deontological theories consider 
consequences as morally significant ${ }^{6}$ and accordingly hold that sometimes (when deontological constraints and permissions do not apply or when they are defeated by clashing consequential considerations) the action whose overall consequences are the best is obligatory, whereas an action whose overall consequences are just slightly less good is wrong.

Moreover, the common distinction between right and wrong actions is taken very seriously. This is demonstrated, inter alia, in the controversy regarding the demandingness of morality. An influential, and persistence, objection to the standard (maximizing) version of consequentialism is that it is overly demanding in its insistence that the action whose overall consequences are the best is always obligatory and all other actions, including, for example, the second best action, are wrong. And consequentialists take this accusation very seriously too. ${ }^{7}$ The extensive debate regarding this question thus demonstrates that the difference between actions that are permissible and actions that are wrong is typically considered to be very important.

This common view regarding the overall moral status of actions extends also to the moral status of agents based on the widely held assumption that the moral status of agents depends (only or also) on the moral status of the actions for which they are responsible. ${ }^{8}$ According to this view, those who are responsible for actions that are obligatory or commendable are praiseworthy, whereas those who are responsible for wrongful actions are blameworthy (others - for example, those whose actions are permissible but not commendable - are often classified

${ }^{6}$ See Rawls 1971: 26 ("All ethical doctrines worth our attention take consequences into account in judging rightness. One which did not would simply be irrational, crazy").

7 See, for example, Scheffler 1982: 7-8; Kagan 1984; Kagan 1989: 1-2; Singer 1993: 229-230; Unger 1996: 56; Murphy 2000; Hooker 2000: 27; Norcross 2006: 218-220.

${ }^{8}$ See, for example, Alexander \& Ferzan 2009: 199-209; Alexander \& Ferzan 2018: 186; Alexander 2018: 532; Gordon-Solmon 2018: 564; Brink 2019: 350. 
as "innocent"). As a result, a common view considers the moral status of agents as discontinuous as well.

Thus, according to the common view, what seems like a small difference in the moral status of the actions and the agents in the self-defense and accident cases, for instance, is in fact a momentous difference: the difference between self-defense that involves reasonable force and self-defense that involves force that is just short of being reasonable, or between driving in a way that is completely reasonable and driving in a way that is just slightly unreasonable, is the difference between an action that is right and an action that is wrong (and between an agent who is praiseworthy, or at least "innocent", and an agent who is blameworthy). If the common view is correct in this respect, the very different legal outcomes in these examples is called for and the Continuity Argument is inapplicable (since its first premise does not apply in these cases).

Of course, the fact that the first premise of the Continuity Argument is incompatible with a common view does not entail that the first premise is false. Indeed, although the common view may seem reasonable - after all, the difference between what we should do and what we should not do does not appear to be trivial - I think that it is misguided. In order to demonstrate that, I evaluate the controversy between the standard (maximizing) version of consequentialism, which is incompatible with the premise that the relevant part of morality is continuous, and the much less common, and more radical, version of scalar consequentialism, which is in line with this premise. I argue that the radical version is more plausible. Thus, I conclude that the first premise of the Continuity Argument is after all safe in this regard, at least regarding the part of morality that is concerned with the overall moral status of actions and agents, but only if we accept a radical and unpopular view (as I think we should).

The second doubt regarding the Continuity Argument concerns its second premise (and, as a result, the conclusion of the argument), namely, the claim that the law should track the relevant part of morality - the one that is concerned with the overall moral status of actions and agents usually. This premise reflects a view regarding the proper resolution of the conflict that often exists in legal contexts (as well as in other practical contexts) between considerations that support an accurate reflection of factors such as the moral status of actions and agents and considerations in favor of simplicity and clarity (as means of achieving other moral goals, such as 
preventing undeserved suffering). (Another familiar context in which this tension exists, in addition to the one that is the focus of the Continuity Argument, is the choice between standards and rules. ${ }^{9}$ ) However, it is important to notice that the foundational considerations both for and against continuity are the same considerations (for example, a reason against undeserved suffering). And since these considerations sometimes support laws that track the relevant part of morality - the moral status of actions and agents - but sometimes oppose such laws, and their applicability and force depend not only on various moral propositions but also on contingent (non-moral) facts, it is difficult to determine the degree to which the law (at a certain place and time) should be continuous, including whether it should be "usually" continuous, without an extensive inquiry regarding numerous empirical questions concerning the effects of many possible laws. Thus, it seems that the tendency to prefer the reasons for, rather than against, legal continuity is at least partly due to a bias towards the short term as opposed the long term. Therefore, I do not think that we have the evidence to determine that the law should be usually continuous, and accordingly that the law (at a certain place and time) is not as continuous as it should be. Indeed, it seems to me that the possibility that the law is, overall, more continuous than it should be is just as likely as the possibility that it is less continuous than it should be.

In response, it may be argued that this laborious inquiry is (sometimes) redundant, since there are some considerations in favor of tracking pertinent continuous moral factors through the law that are always, or at least almost always, decisive, for example, considerations against using the criminal law against actions that are permissible or against agents who are not blameworthy (or

${ }^{9}$ Kolber suggests that the questions concerning the choice between standards and rules, on the one hand, and continuous and discontinuous laws, on the other hand, are related in a way that is merely superficial (Kolber 2014: 668). But I think that in terms of the most important issue - the considerations for and against each of these alternatives - there is no difference between these questions. 
in a way that does not reflect the degree to which actions are wrong or agents are blameworthy). However, I argue that this objection is implausible. Indeed, it is implausible due to the continuous nature of the pertinent factors. On the one hand, the force of the considerations against undeserved punishment is not (almost) always very strong. On the other hand, there are sometimes strong clashing considerations, for instance, when enacting and enforcing overinclusive criminal prohibitions is the only way to prevent serious harm to (virtuous) persons.

The paper considers these doubts. I begin by exploring the doubt regarding the first premise, namely, the continuous nature of the relevant part of morality, while focusing especially on the objection that there is an important difference between wrongful and permissible actions (Section 2). I then consider the doubt regarding the second premise, while pointing out that the considerations for and against tracking the relevant part of morality through the law are, ultimately, the same considerations and explaining why I believe that the claim that the former considerations are always decisive is doubtful (Section 3). Finally, I consider, more specifically, some aspects of the controversy regarding partial defenses in the criminal law, since this discussion illustrates several points that are relevant to the Continuity Argument in its general form. This is because some of the arguments for and against partial defenses focus on the degree to which morality is continuous in various respects and on the extent to which the law should be continuous as well in order to reflect moral continuity. This discussion has some interesting implications, for example, that when the difference between actions that are permissible and actions that are wrong only in the sense that they are not perfect is trivial, there does not seem to be much point in distinguishing between complete and partial justificatory defenses to begin with (Section 4).

My focus throughout the paper is the Continuity Argument whose focus is the question of what the law should be. I will for the most part ignore the auxiliary argument regarding positive law. Obviously, these arguments are related. Specifically, the discussion of the Continuity Argument is relevant to the auxiliary argument as the latter argument assumes the conclusion of the former. But the auxiliary argument requires also the evaluation of the degree to which positive law (at various places and times) is continuous, not only in terms of more formal expressions of the law (such as legislation) but also in terms of the way they are implemented, 
for instance, the way in which judges employ their discretion regarding matters such as sentencing in the criminal law and compensation in tort law.

\section{The First Premise: Scalar Morality}

Our first question is thus the degree to which morality is continuous. Specifically, the question concerns the part of morality that is the focus of the Continuity Argument, namely, the overall moral status of actions (and agents to the extent to which the two are related). Before considering this question directly, however, I begin with a few comments regarding the degree to which the pro tanto factors that affect the overall moral status of actions are continuous. The common view is that even if all of the pro tanto considerations are continuous, there is one respect in which the overall moral status of actions is discontinuous, namely, the distinction between permissible and wrongful actions. However, it seems reasonable to assume that the degree to which the pro tanto factors that are relevant to the moral status of actions are continuous affects the degree to which the overall moral status of actions is also continuous. The more continuous are the relevant pro tanto factors, there is more reason to assume that the all things considered conclusion that reflects the balance of these considerations is also continuous. Indeed, to the extent to which the pro tanto factors are not continuous there is no (or at least much less) reason to assume that the overall moral status of actions is continuous, and accordingly there is not even a prima facie case for the first premise of the Continuity Argument.

The main conclusions are that consequences-based considerations are more often continuous than deontological ones. However, there are important respects in which consequences-based considerations are discontinuous and deontological considerations are continuous. It is also important to recall that standard deontological theories include also consequences-based considerations and are thus continuous to the degree to which these considerations are continuous. The following discussion of the degree to which morality is continuous is of course not exhaustive; its goal is mainly to consider the challenge that the common view presents to the first premise of the Continuity Argument regarding the overall status of actions (and consequently agents). 
One preliminary clarification is important before we continue. Considering the degree to which (the relevant part of) morality is continuous is complicated due to the controversies regarding the question of which facts are morally significant (at all or in the relevant respect). Indeed, the moral significance of each of the factors that are considered below is controversial. Exploring which of these factors is indeed morally significant is obviously beyond the scope of this essay. I therefore consider the degree to which salient factors that are often considered to be morally significant are continuous, while assuming, for the sake of the discussion, that they are morally significant (in the relevant respect).

However, there are several controversies that it is important to flag in this context. One is whether, or in what way, the moral status of an action is morally significant in itself for the response to this action, including the legal response. A common view holds that the (overall) moral status of an action is relevant as such to the justification of the (inter alia legal) response to this action, for instance, that there is a reason to prevent wrongful actions or to punish agents whose actions are wrong. In contrast, I think that the moral status of actions is not important in itself with regard to the response to this action, inter alia, through the law; I believe that the moral status of actions matters in this respect only if and to the degree to which it is related to the moral status of agents and to the moral status of the consequences of the actions. ${ }^{10}$ However, since the former view is often assumed in discussions of the Continuity Argument, ${ }^{11}$ I sometimes

${ }^{10} \mathrm{I}$ argue for this view in Segev Draft 1.

${ }^{11}$ See Section 3. Kolber, for example, appears to accept this view when he considers the self-defense and the accident examples. See Section 1. Kolber sometimes refers in this context to the moral status of agents in addition to or instead of the moral status of actions, but it seems that this assumes that the two are related. 
assume it, for the sake of the discussion, in order to consider other issues that pertain to the continuous nature of morality.

Another pertinent question is whether what matters for the moral status of actions are the morally significant facts or the (actual or justified) beliefs of the agents regarding these facts. (According to a third view, both of these factors matter, in different ways, to the moral status of actions.) I think that the most plausible view is that at least the most basic sense of the moral status of their actions (as opposed to the moral status of the agents) is concerned with facts and not with the beliefs of agents. ${ }^{12}$ However, since the former view is often assumed in discussions of the Continuity Argument, ${ }^{13}$ I sometimes assume, in what follows, that beliefs matter in this respect.

Finally, another controversy concerns the relation between the moral status of actions and the moral status of persons. A common view relates these issues by assuming that the moral status of agents depends, either only or at least also, on the moral status of their actions, namely, that a person who is responsible for a right action is, in this respect, praiseworthy, whereas a person who is responsible for a wrong action is, in this respect, blameworthy. Another view holds that the moral status of persons depends on their character or mental states and not on their actions. While the latter view may be more plausible, the former is very common, especially in the context of the Continuity Argument, and therefore I often assume it, for the sake of the discussion.

${ }^{12}$ I discuss this question further and explain what I mean by "the most basic sense" in Segev 2012.

${ }^{13}$ Kolber, for example, seems to assume that the beliefs of agents are important to the moral status of their actions when he considers the self-defense and the accident examples (assuming that what is "reasonable" in the relevant respects refers, inter alia, to various probabilities and that probabilities are relevant only in the framework of beliefs). 


\subsection{Pro Tanto Considerations}

The first question is thus the degree to which the basic pro tanto components that affect the overall moral status of actions (and agents) are continuous. There are salient pro tanto reasons that appear to be continuous in some respects. These include mainly some aspects of influential consequential reasons. One type of examples concerns reasons whose currency is the well-being of individuals, since the facts that affect the degree to which the life of a person is good (her wellbeing), such as her happiness, seem to be, at least mostly, a matter of degree. Accordingly, the force of reasons whose currency is well-being appears to be continuous. These include, for example, the reason to maximize the well-being of individuals; the view that the reason to maximize individual well-being is stronger the worse-off the person is ${ }^{14}$; the reason to minimize inequality in terms of well-being ${ }^{15}$; and the reason that the level of individual well-being reflects what the relevant person (morally) deserves, in light of her actions, intentions, or character. Deontological reasons whose currency is well-being appear to be continuous in a similar way. These include deontological variations of distributive and retributive reasons, for instance, a deontological reason to act in a way that is equal, in terms of well-being, and a deontological reason to act in a way that gives people what they deserve, in terms of well-being. (There reasons are different then consequences-based reasons since they focus on the effects of one's action rather than on other factors that affect well-being.) And this is the case regarding other aspects of distributive and retributive considerations as well. For example, plausible accounts of

\footnotetext{
${ }^{14}$ See Parfit 1997.

${ }^{15}$ Although it is difficult to measure the degree of inequality when more than two persons are involved (see Temkin 1993: 50-52), it seems reasonable to assume that at relevant variables are also continuous.
} 
considerations of desert, such as those that consider the beliefs of people as relevant to the question of what these people deserve, appear to appeal to continuous notions, for instance, to the extent that beliefs are probabilistic.

There are, however, several aspects of morality that do not appear to be continuous in the relevant way. First, consequences, and accordingly considerations regarding consequences, are discontinuous in an important respect: actions that are very similar, and even identical, in every way that is morally significant may have very different consequences (that are morally significant): some actions cause harm, for example, while others do not (and some harmful actions cause much more harm than other harmful actions).

It is uncontroversial that (some) consequences of actions are morally significant in several ways. First, some states of affairs are morally good or bad, for example, other things being equal, a state of affairs in which a person suffers undeserved harm is worse than a state of affairs in which she does not. Second, according to a plausible and common view, the overall moral status of actions also depends on their consequences (according to another view, what matters in this respect is the beliefs of the agents regarding the morally significant facts). Third, there is a reason to prevent actions whose overall consequences are not optimal, as a means of preventing these consequences (inter alia by legal means). Finally, according to another (more controversial) view, the moral status of agents - the degree to which they are praiseworthy of blameworthy - also depends (not only on their actions but also) on the consequences of their actions, even when these consequences are a matter of luck (another view rejects this type of moral luck and holds that the moral status of agents is not affected by their consequences). These views are discontinuous in that they judge very differently actions and agents that are very similar (or even identical) in all of the relevant moral respects, apart from their consequences.

It may be objected that the proposition that actions that are very identical in every morally significant respect may have very different consequences is incoherent since the consequences of actions are a constitutive element of the actions. However, even if we assume, for the sake of the argument, that this is the case, this objection does not affect the main point, namely, that a difference that is small in terms of one factor that is morally significant (the constitutive aspects of actions apart from their consequences) sometimes generates a dramatic difference in another 
factor that is morally significant, namely, the consequences of actions. Whether or not we describe the first factor as all of the factors that affect the moral status of actions, as my initial proposition did, or as part of the factors that affect the moral status of actions, as the objection suggests, is not important in this respect.

Kolber seems to downplay these respects in which morality is less continuous due to luck in two ways. First, he sometimes points out that "dangerousness" - the probability, given the available evidence, that a person would perform an action whose consequences are not optimal - is a matter of degree, and assumes that this factor is relevant to the law, namely, that, for example, the degree to which a person is dangerous affects the force of the reason to punish her. ${ }^{16}$ However, first, even if this factor - the justified beliefs of agents - is important in relevant ways (and this is controversial), it is plausible to assume that actual consequences - rather than the probability of their occurrence - are also morally significant in other ways that are relevant to the law. Second, Kolber says that views that embrace moral luck are compatible with the assumption that morality is continuous since they merely consider another continuous variable, for example, harm, as morally significant. ${ }^{17}$ However, while the latter claim is correct, the former is inaccurate. There is an important sense in which views that endorse moral luck are discontinuous, for they hold that the moral status of agents whose actions are (otherwise) very similar may be very different. Indeed, Kolber himself often emphasizes that the legal status of very similar actions may be very different due to this difference, namely, when one action results in harm and one does not (for instance, since the law of torts requires compensation only when

\footnotetext{
${ }^{16}$ Kolber 2016: 858.

${ }^{17}$ Kolber 2016A: 859-860.
} 
there is harm).$^{18}$ According to views that endorse moral luck, this - non-continuous - legal position may be justified, even assuming that what matters in terms of the justification of the relevant law is the degree to which the agent is blameworthy.

Another factor that does not seem to be completely continuous concern considerations of desert. Such considerations often regard (also or only, some of) the intentions of people (for example, the intention to harm a person or to benefit a person) as affecting the degree to which they are deserving. But at least in some ways that are often considered as significant in this respect, the difference between having a certain intention and not having it is not a matter of degree. Accordingly, considerations of desert that appeal to intentions are in this respect discontinuous. (This is true with regard to both consequential and deontological considerations of desert.)

Finally, salient deontological constraints are discontinuous in several ways. Consider, for example, the most common versions of deontological constraints, such as those that forbid harming people, or harming people intentionally, or using people as means. There is an important difference, according to these views, between, for example, killing a person and letting a person die, or between killing a person intentionally and not killing a person intentionally (including killing a person in a way that is not intentional), or between using a person as a means and not doing so. Accordingly, the overall moral status of these actions is very different. Of course, the extent to which this is the case needs to be considered with regard to other deontological constraints as well, but it seems safe to conclude that at least (the most) salient deontological constraints are discontinuous in the way that common consequential considerations are.

${ }^{18}$ Kolber 2016A: 876. 
There are, however, several senses in which common deontological constraints are nevertheless continuous. First, these constraints appear to be continuous to the extent to which they are sensitive to probabilities, for example, if they apply only beyond a certain probabilistic threshold, for instance, forbid creating a certain level of risk of harming a person. ${ }^{19}$ For the difference between lower and higher probabilities is presumably (at least for the most part) gradual. Second, some accounts determine the scope of deontological constraints also in light of consequential factors. According to one view, for example, deontological constraints do not apply when there are (very) strong consequential reasons in favor of an action that is otherwise within the ambit of the constraint. (Another view is that such consequential reasons do not affect the scope of the constraint but may clash with the deontological reason and defeat it.) To the extent that these consequential considerations are continuous, the deontological constraints whose scope depend on them are also continuous.

Finally, according to some views, morality is, to a certain extent, vague. For example, some think that deontological constraints are decisive unless the force of clashing consequential reasons crosses a certain threshold and that this threshold is vague. ${ }^{20}$ This view may be relevant to the degree to which morality is continuous. On the one hand, the claim that (a certain aspect of) morality is vague assumes that there are important moral boundaries: that some actions are permissible and some are not, for example; it just adds that some other (borderline) actions are neither. On the other hand, if morality is vague to some degree, this does make it more continuous in another sense, namely, that the line between what is permissible and what is not,

\footnotetext{
${ }^{19}$ For discussion, see, for example, Alexander 2000: 904-905.

20 For this controversy, see, for example, Shafer-Landau 1995; Alexander 2008; Eklund 2011; Constantinescu 2014; Schoenfield 2016.
} 
for example, is not sharp. However, notice that the implications of moral vagueness with regard to questions such as what people deserve, for instance, are not obvious.

To conclude: it appears that some salient pro tanto factors, which are relevant to the overall moral status of actions, are continuous, but others are not. Generally, it seems that consequential factors tend to be more continuous than deontological ones, although the former are not completely continuous and the latter are not completely discontinuous. ${ }^{21}$ Therefore, the first premise of the Continuity Argument, according to which the overall moral status of actions is continuous, is more plausible in accordance with the degree to which the relevant part of morality (the pro tanto factors that affect the moral status of actions) includes more consequential factors, and especially assuming a consequentialist view according to which all of the relevant factors are consequential. In this respect, the Continuity Argument depends on the controversy between consequentialism and deontology. Accordingly, the first doubt regarding the first premise of the Continuity Argument, that I consider below, is important especially assuming consequentialism. ${ }^{22}$

\subsection{The Overall Moral Status of Actions \& Agents}

We can now consider the main doubt regarding the first premise of the Continuity Argument, namely, whether, or to what degree, is the overall moral status of actions continuous and, specifically, what is the significance of the difference between the best action and other actions,

${ }^{21}$ See Alexander 2008.

${ }^{22}$ Katz 2011 consider other claims regarding the degree to which morality is continuous. 
including the second best action and, even especially the second best action that is very similar to the best action in terms of the factors that are morally significant, such as their consequences.

This question is particularly relevant to the Continuity Argument not only because the answer affects the degree to which the relevant part of morality is continuous, but also for other reasons. First, the arguments for and against the competing answers to this question are similar in an important respect to the arguments concerning the second premise of the Continuity Argument that is concerned with the degree to which the law should be continuous: both types of arguments focus on the question of whether a continuous input should entails a continuous output. Second, if the common assumption that the moral status of actions affects the moral status of agents is correct, the degree to which the former is continuous affects also the degree to which the latter is continuous.

Therefore, it is interesting to notice that the common view, which is accepted by both consequentialists and deontologists - considers the overall moral status of actions as discontinuous: it attaches a lot of significance to the difference between actions that are right obligatory or at least permissible - and actions that are wrong, even when the input - the pertinent pro tanto factors that affect the overall moral status of actions - are all continuous.

Kolber does not consider the incompatibility of the Continuity Argument with this common view. He seems to assume that the overall moral status of actions is continuous. Indeed, his main examples for the continuous nature of morality, such as the self-defense and the accident examples, refer to the overall moral status of actions (and agents based on the assumption that these are related). He assumes that the difference between actions that are right ("reasonable") and actions that are wrong is sometimes small (when the latter actions are "unreasonable" only to a small degree - and in that sense not very different from the former, "reasonable", actions). And he does not consider the objection that there is an important difference between right and wrong actions although this objection appears to be entailed by the common view in this regard.

The contrast between the common view and the first premise of the Continuity Argument is especially interesting in the context of a consequentialist account, in light of the conclusion that considerations relating to consequences are more continuous than deontological ones. Indeed, it seems that at least the overall evaluation of states of affairs is commonly assumed to be 
continuous. All consequentialist accounts rank states of affairs from the best to the worse, and while the nature of the differences between (better and worse) states of affairs depend on the content of, and accordingly vary in accordance with, different consequentialists theories, it seems that at least typically these differences are assumed to be continuous. For example, all consequentialist theories appear to consider the degree to which the suffering of virtuous persons (who do not deserve to suffer) is bad as continuous. Therefore, it is interesting to consider the controversy between the common view and the view that the overall status of actions is wholly continuous in light of the arguments in the debate between standard (maximizing) consequentialism, which follows the common view and endorses a dichotomous (discontinuous) distinction between right and wrong actions, even when all the relevant pro tanto considerations are continuous, and scalar consequentialism, which seems to imply that this distinction is trivial.

Larry Alexander claimed that the problem of explaining binary conclusions that seem to reflect scalar properties is only a problem for deontological accounts but not to consequentialist ones. ${ }^{23}$ However, (standard) consequentialist accounts face this problem too in an important respect, which is in one sense even more pressing: since such accounts assume that the basic moral properties are more continuous (compared to deontological accounts), it is especially puzzling that they adopt a binary view regarding the moral status of actions.

The controversy between standard (maximizing) consequentialism and scalar consequentialism focuses on the overall moral status of actions. Both begin with the same account of what is good and bad: a ranking of states of affairs from the best to the worse. They

${ }^{23}$ Alexander 2008: 86. 
differ, however, regarding the deontic implications of this evaluation. Standard consequentialism holds that it is always obligatory to perform the action whose overall consequences are the best, and accordingly that it is always wrong to perform every other action, including actions whose overall consequences are just slightly less good than the best. In this way, standard consequentialism draws a sharp, dichotomous, discontinuous distinction between actions that are right and actions that are wrong. (For this reason, standard consequentialism is considered to be a very demanding theory, since the only action that is not wrong may involve a high cost to the agent.)

In contrast, scalar consequentialism ranks actions in the same way that every consequentialist theory ranks states of affairs, from the best to the worse, while noting the degree to which each action is better or worse than other actions. Scalar consequentialism accordingly entails that there is a reason in favor of performing an action that is better rather than an action that is worse, and accordingly a reason against performing an action that is worse rather than one that is better; that the force of these reasons depends on the degree to which the relevant action is better, or worse, than alternative actions; and, finally, that there is most reason to perform the best action (the one whose consequences are the best). However, scalar consequentialism does not classify actions as obligatory, permissible, or wrong (to the degree to which these terms go beyond the former evaluations). (Scalar consequentialism is therefore often considered to be less demanding than standard consequentialism.)

A few points regarding this controversy are worth noting at the outset. First, the controversy concerns the theoretical question of what is the accurate way of depicting the relevant part of morality - and not the practical question of what is the most useful way of talking, for example. (In the latter respect, the answer is presumably different in different factual settings.)

Second, the controversy focuses on the standard (maximizing) and the scalar versions of consequentialism. But it seems to be relevant also to other forms of consequentialism. Specifically, it is relevant to satisficing consequentialism, which holds that every action whose 
overall consequences are "good enough" is permissible. ${ }^{24}$ For this version too, like the standard, maximizing, version, draws a sharp line between what is permissible and what is wrongful -albeit a different one. Therefore, salient arguments for and against the standard (maximizing) version of consequentialism, which focus on this shared feature, apply also to satisficing consequentialism.

Scalar consequentialism presents a radical option relative not only to other forms of consequentialism, but also to standard deontological theories, and indeed more generally to common, including less theoretical, accounts of morality, all of which distinguish between actions that are right (obligatory or at least permissible) and actions that are wrong (those that violate a duty). ${ }^{25}$ Is this radical option plausible then? Here are the arguments that I find most compelling in the debate between standard and scalar consequentialism. ${ }^{26}$

I think that the most compelling argument in favor of scalar consequentialism, and against the standard forms of consequentialism, is that the scalar option reflects all the morally significant facts, and only these facts, with regard to the overall moral status of actions, by ranking states of affairs and actions from the best to the worse; whereas the standard versions assign weight to facts that are not morally significant by distinguishing between actions that are right and actions

${ }^{24}$ See, for example, Slote and Pettit 1984.

${ }^{25}$ The radical nature of scalar consequentialism is emphasized, for example, by Hooker 2006: 239.

${ }^{26}$ There are other arguments in favor, and against, scalar consequentialism that are unsound, it seems to me. One example is the claim that the force of the reason to influence a person to do more good does not depend on the question of whether, as a result, her action would be obligatory or not (see Norcross 2006: 220-221). While the conclusion of this argument is correct, I think that this is the case because the overall moral status of the action of one person is not, in itself, a reason for or against the actions or others, in light of or in response to the former action (see Segev draft 1). Therefore, this conclusion does not support scalar consequentialism. 
that are wrong in ways that go beyond the scalar ranking. ${ }^{27}$ The scalar version reflects all the pertinent morally significant facts, and only these facts, by ranking alternative actions from the best to the worse, while noting the degree to which each action is better or worse than alternative actions, and accordingly the force of reasons for and against every alternative action, compared to all other possible actions. Indeed, the scalar view accurately reflects the fact that the degree to which actions are sensitive to the pertinent considerations, especially those that focus on consequences, appears to change gradually. Finally, the scalar version does not refer to facts that are not morally significant (in the relevant respect, that is, to the overall moral status of actions).

The standard version, in contrast, assigns too much weight to the distinction between the best possible action and all other alternative actions, by classifying the best action as right - indeed as obligatory - and all other actions as wrong. This dichotomous distinction is misleading in several related ways. Generally, it is misleading since actions reflect the pertinent moral considerations in better and worse ways. And it seems that at least according to plausible and common accounts (especially but not only consequentialist ones), a significant part of this spectrum is continuous. Moreover, the overall evaluation of states of affairs appears to be at least mostly continuous, according to plausible and common accounts, and it is implausible to assume that the best action is necessarily and thus always very different from all other actions. ${ }^{28}$

More specifically, the dichotomous distinction between the best action and all other actions is misleading, first, in its treatment of the best action compared to actions that are not far from

${ }^{27}$ For arguments in this spirit, see Norcross 1997; Norcross 2005; Norcross 2006; Norcross 2006A; Tobia 2017; Seinhababu 2018.

${ }^{28}$ See Segev 2010: 69. 
it. That is, the standard versions of consequentialism draw a sharp distinction between the best action (the "right" and indeed the "obligatory" one) and actions that are very similar to the best action in terms of all the underlying moral factors. For example, scalar consequentialism often grades the best action as perfect $(\mathrm{A}+$, or $100 \%$, say), and a second best action that is almost as good as the best, as almost perfect (A, or 98\%, for example). In contrast, the standard, maximizing, version of consequentialism describes the latter action as wrong (F!) - although it is almost perfect in terms of its overall consequences.

In addition, the dichotomous distinction of standard consequentialism is misleading in that it classifies all actions that are not the best together - as wrong - although there may be (and often are) huge differences between them (in ways that are morally significant): the second best option may be almost perfect, for example, whereas the worse option may be awful. And yet both are classified by the standard version of consequentialism together as wrong.

Indeed, the latter difference, between the second best action which ranks very high, although it is not perfect, and the worse, awful, option, is typically much more significant than the difference between the best action and the second best action that is almost perfect. Since there are typically numerous alternative actions, and there are substantial differences between many of them, the scalar version evaluates common actions - which are typically neither the best nor the worse and indeed far from both the best and the worse options - more accurately than the standard version. Consider, for example, how much money should a certain well-off person give each month to the people who are overall most deserving (say, in terms of their level of wellbeing and their level of virtue), taking into account the good effects of the action, on the one hand, and its cost to the agent, on the other hand. Assume that giving US\$1000 would have the best consequences overall, that giving US\$990 would have overall consequences that are almost as good - just slightly less good than giving US\$1000, and that giving nothing would have overall consequences that are very bad. The standard, maximizing, view considers giving US\$1000 as obligatory and giving both US\$990 and nothing as wrong.

To be sure, the standard account of consequentialism may, and typically does, recognize that there may be important differences between actions that are all classified as wrong: some are worse than others. However, the standard account still classifies all of these actions as wrong - 
and this classification appears to be not only redundant - since it adds nothing that is morally significant to the ranking of actions, from the best to the worse - but also misleading - because we usually introduce classifications only when they are informative.

The essence of this argument against the standard, maximizing, version of consequentialism applies also against the less common version of satisficing consequentialism. For this version too draws a dichotomous distinction between actions that are permissible and actions that are wrong - between actions whose overall consequences are "good enough" and other actions - although the difference between the former and the latter actions, in terms of their overall consequences, may be trivial. Even if the line that separates actions whose overall consequences are "good enough" and other actions is vague, it is still the case that satisficing consequentialism distinguishes between actions that are wrong and actions that are right in a way that goes beyond the underlying differences between their consequences.

In these respects, the scalar version reflects the overall moral status of actions better than the maximizing and the satisfying versions of consequentialism, especially since the latter versions seem to attach too much significance to trivial differences. Regardless of where the line is drawn by the maximizing and the satisfying versions, the difference between some actions that are classified as right and some that are classified as wrong may be very small, while the differences between actions that are all classified as wrong may be huge, due to the continuous nature of the relevant variables.

These advantages of the scalar account with regard to the evaluation of the moral status of actions carry over to the evaluation of the moral status of agents to the extent to which people are praiseworthy or blameworthy in light of their actions. In addition, even if, or to the degree to which, the moral status of agents does not depend on the moral status of their actions, it seems that similar arguments apply in favor of a scalar version of the moral status of agents.

The main argument against scalar consequentialism, and in favor of standard consequentialism, is that a moral theory should include not only evaluative components but also deontic components and specifically identify what should - and what should not - be done, and 
in this way provide guidance to people. ${ }^{29}$ According to this line of thought, first, the best action is qualitatively and not only quantitatively different than the second best action, even if the overall consequences of the latter are just slightly less good than those of the former, since the best action is the one that should be performed. A similar claim against scalar consequentialism is made with respect to the other side of the spectrum: that some actions should be classified as wrong, for example, torturing people for fun. ${ }^{30}$

Despite its intuitive appeal, however, I think that this objection is unpersuasive. It seems to me that the scalar view reflects all the morally significant information (and provides proper guidance) in the relevant respects. In contrast, the standard version adds propositions that are either redundant or mistaken, depending on how terms such as "right" and "wrong" are understood. While making claims about the rightness or wrongness of actions may be useful sometimes, they do not add information that is morally significant.

Notice, first, that a scalar account does point out which action is the best and accordingly which action is the most commendatory and which action there is most reason to do. It does not classify this action, in addition, as obligatory, but this classification adds nothing that is morally important to the former propositions, it seems to me.

Moreover, a scalar account points out not only which action is the best but also, with respect to each action, if it is better, or worse, relative to every other possible action, and by how much. Accordingly, a scalar account entails reasons for and against each action, compared to every alternative action, and points out the force of such reasons: that the reason to prefer one action over an alternative one is (much or just slightly) stronger, or weaker, than the reason to prefer

\footnotetext{
${ }^{29}$ See Lawlor 2009.
}

${ }^{30}$ Hooker 2006: 239. 
the former action to a third alternative action, for example. This is important given that most actions (both possible actions and typical actions) are neither the best nor the worse but rather somewhere in between these extremes: they are better than some alternatives - much more than some, slightly more than others - and worse than some alternatives - again, significantly more than some and merely trivially more than others. Thus, the scalar account points out that there are reasons not only in favor of the best action but also in favor of actions that are not the best - since they are better, often much better - than other alternative actions, as well as reasons against them, to the extent that they are worse than others. ${ }^{31}$

Is there something that a scalar account still misses, compared to the standard account? Specifically, do terms such as "duty" or "obligation" add information that is morally significant to the information that the scalar account provides? It seems to me that the answer is negative. Any classification that goes beyond the information provided by the scalar view - including one that is based on terms such as "duty" - is not only redundant but also arbitrary and misleading, since it implies that such information does exist.

It is important to recall that this conclusion concerns the theoretical question of what is the accurate way of depicting the relevant part of morality and not the question of what is more natural to say in some contexts or the practical question of what is more useful to say. It may well be more natural to depict certain actions as, simply, right or wrong, rather than, for example, the best (this is partially just because the common view is, well, common, but perhaps not only). This may be the case, for instance, since sometimes it is sufficient to focus on the most salient options. Indeed, typically most options are not salient, inter alia, in the sense that the relevant

${ }^{31}$ See Norcross 1997: 32; McElwee 2010; Seinhababu 2018. 
agent does not consider them seriously (and indeed does not even notice most of them). And with regard to the (often very few) salient options, it is sometimes clear that one is much better, or worse, than the others. It such cases, it may be less cumbersome, although less accurate, to describe the relevant actions as obligatory and wrong, rather than as better and worse, to various degrees, than all of the alternatives. But this does not affect the conclusion that what is fundamentally more accurate is the latter option (taking into account, inter alia, the fact that with regard to most actions that are naturally described as wrong, there are even worse alternative actions, for example). It may also be more useful sometimes to use terms such as "duty" and "wrong", when this brings about optimal consequences on balance, in term of influencing the actions of people (who are not perfect). ${ }^{32}$ But this too is irrelevant to the present discussion. (Therefore, to the extent that the above objection is concerned with guidance in this practical sense, it is irrelevant.)

It thus seems to me that the less common and more radical option of scalar consequentialism is more plausible than the standard option of maximizing consequentialism (and the option of satisfying consequentialism), at the end of the day. The stark distinction between permissible and wrongful actions is out of place at least given a consequentialist outlook. Accordingly, the first premise of the Continuity Argument is reasonable at least regarding the parts of morality that are concerned with the overall moral status of actions and agents, but only if we accept, as I think we should, a radical and unpopular view.

\footnotetext{
${ }^{32}$ However, it is also worth noting that this is not obvious. Indeed, it is reasonable to assume that sometimes the opposite is the case and that the more accurate view is also the more useful one. Perhaps, for example, some people would be willing to help others more if we say just what is better, or worse, than if we say that only a certain action is the right one, and all others are wrong, since they find the former action as too demanding.
} 
The extent to which this conclusion is radical depends on the meaning of terms such as "duty" and "wrong". At one extreme, if their meaning were merely something like the best and the worst (or similar notions such as "good enough" and "very bad"), respectively, and they come in addition, rather than instead of, other terms that emphasize the continuous nature of morality, mainly comparative notions, then there is no theoretical difference between the scalar version and other versions. Of course, in this case, these terms are redundant and misleading. However, to the extent to which terms such as "duty" and "wrong" are understood in the more common way, which is more robust, then there is a difference between the scalar version and other versions, and this difference is more significant in accordance with the degree to which the meaning of these terms goes beyond the prescriptions of the scalar version. Therefore, if the traditional, inflated, meaning of these terms is entrenched, discarding them would lead to propositions that are more accurate. ${ }^{33}$

My conclusion is thus that the first premise of the Continuity Argument is plausible, at least regarding the part of morality that is concerned with the overall moral status of actions and agents. However, it does not follow from common assumptions regarding the nature of (the relevant part of) morality and indeed it is compatible only with a minority view in this regard. Therefore, in order to clear the way to the Continuity Argument we need to consider the arguments for and against this view.

${ }^{33}$ This discussion may of course have other lessons, for example, regarding the question of whether consequentialism, or other moral theories, are too demanding. 


\section{The Second Premise: The Morality of Law}

The second doubt regarding the Continuity Argument is about its second premise, according to which the law should track the relevant part of morality - mainly the overall moral status of actions and agents - usually.

The fact that the Continuity Argument focuses on the part of morality that is concerned with the overall moral status of actions and agents is important in this regard. For if the relevant part of morality is rather the all-things-considered moral conclusions about the law, it is of course trivially true that the law should track morality (not only usually but always). Clearly, the law should align with the all things considered moral conclusions regarding the question of what the law should be.

While trivial in this sense, this interpretation of the second premise of the Continuity Argument is important in another way, since it highlights a fact that is important also to the nontrivial interpretation of this premise (the one that is concerned with the overall moral status of actions and agents), namely, that the answer to the question of what the law should be depends on the conclusions that follow from the interaction of all the applicable considerations. Therefore, when we consider whether (or when) the law should track the overall moral status of actions and agents, we should bear in mind that there are often not only pro tanto reasons in favor of legal continuity but also reasons against legal continuity. Moreover, it is important to notice that the relevant considerations for and against continuity are, ultimately, the same considerations, for example, considerations against undeserved suffering or in favor of maximizing well-being, and that the applicability and the force of these considerations depend not only on various moral propositions but also on contingent non-moral facts. For example, there is desert-based reason in favor of legal sanctions that accurately reflect the degree to which the relevant persons are blameworthy, but there is also a desert-based reason against such a law when a law that tracks blame less accurately prevents more undeserved suffering, for instance, if it prevents (intentional or unintentional) actions that cause undeserved harm more efficiently or it is less costly and the resources that a more accurate tracking requires may prevent the suffering of innocent persons if used elsewhere. That is, it should be noticed that, according to a 
plausible account of desert, a desert-based reason is pertinent not only to the agents but also to their victims.

Accordingly, the degree to which the law (at a certain place and time) should track the relevant part of morality depends on moral and empirical questions concerning, inter alia, the effects of numerous alternative laws. Consequently, in order to determine if a certain law should track the relevant part of morality (more or less accurately), including whether it should do so usually, as the (second premise of the) Continuity Argument holds, an extensive inquiry regarding these (moral and) empirical questions is required. Therefore, I do not think that we have the evidence to determine that it is more likely that the law (at a certain place and time) should track morality usually (or less than it in fact does).

Kolber occasionally acknowledges that the overall moral conclusion may be that the law should not be continuous sometimes, since the considerations in favor of legal continuity may be defeated by opposing considerations. ${ }^{34}$ However, he emphasizes mainly the former considerations (in favor of legal continuity) while underplaying, and occasionally even ignoring, the latter (against legal continuity). He sometimes says, for example, that the former are considerations of "justice", whereas the latter are "practical" considerations. ${ }^{35}$ This is misleading since these are the same foundational considerations. He also writes often that when a law does not track a continuous moral factor, morally significant information is "destroyed" or, alternatively, that there is a "rounding error", since morally significant continuous information is not reflected in the law. ${ }^{36}$ This is misleading in two related ways. First, moral information is not

\footnotetext{
${ }^{34}$ Kolber 2014: 687.

${ }^{35}$ See, for example, Kolber 2014: 659.

${ }^{36}$ Kolber 2014: 663, 682.
} 
lost when a consideration against legal continuity defeats a consideration in favor of continuity: the latter is not ignored but is weaker than a clashing consideration. For the same reason, it is misleading to say that there is a rounding error when a consideration in favor of continuity is defeated, since, by hypothesis, there is no error when a decisive consideration is followed and a consideration that is defeated is not followed. To be sure, there is a morally significant cost in this case, but since this cost is, again by hypothesis, less significant than the cost involved in the alternative course of action, there is no error. Second, even the misleading sense in which morally significant information is lost (or there is a rounding error) applies equally if a consideration against legal continuity is defeated.

In response, it may be argued that sometimes the law should track the overall moral status of actions and agents regardless of the consequences of doing so, since there are considerations in favor of tracking continuous moral factors through the law that are always, or at least almost always (and not only usually), decisive. The most common suggestion focuses on considerations against undeserved legal sanctions, that is, legal sanctions that do not reflect the degree to which the relevant actions are wrong or the relevant agents are blameworthy (including of course actions that are not wrongful or agents who are not blameworthy at all).

This suggestion seems to me implausible. In order to see why, we should begin by noting that the value of the law is merely instrumental: the law is merely a means and not a goal. In other words, the law is never a constitutive element of foundational - the most basic - moral standards. Foundational moral standards do not refer to the law, and standards that do refer to the law are not foundational but rather derive from more basic ones. This observation has several related implications. The first is that the fact that a certain moral factor - such as the overall moral status of actions - is continuous, is not in itself a reason for or against a law of a certain type. Rather, there is a reason in favor of a law that tracks this factor only if such a law promotes a value that 
is independent of the law. ${ }^{37}$ For example, there is no foundational consideration against undeserved legal sanctions but rather against the undeserved effects of the law in terms of a value that is independent of the law. According to one suggestion, for example, what culpable wrongdoers deserve is defined in terms of wellbeing. For instance, they deserve to suffer (in proportion to their culpability). This view is defined independently of the law (and thus could be promoted also by non-legal means). Therefore, it is compatible with the assumption that the value of the law is merely instrumental. In contrast, views according to which the foundational currency of desert is the law itself (for example, that culpable persons deserve legal punishment), ${ }^{38}$ are incompatible with this assumption and are therefore implausible, it seems to me.

The observation that the law is merely a means implies that both the reasons in favor and the reasons against a law that tracks a continuous moral factor are instrumental reasons whose force is derived from more basic reasons. Therefore, the reasons for and against any law are ultimately the same type of (foundational) reasons. Thus, the relevant conflict in not between different types of considerations - for instance, between considerations of "justice" and "pragmatic" considerations - but rather between reasons of the same type. For example, while the reason against undeserved suffering sometimes supports, in one respect, a (continuous) law that accurately tracks the degree to which a person is blameworthy, the same reason may also oppose such a law - namely, support a law that is discontinuous, in another respect, for example, if it prevents (intentional or unintentional actions that cause) undeserved harm more efficiently or it

\footnotetext{
${ }^{37}$ See Segev 2017.

${ }^{38} \mathrm{It}$ is sometimes claimed, for example, that retribution is a political value in the sense that only the state can promote retribution by imposing legal punishment. Compare Hampton 1992: 1694; Binder 2002; Duff 2014: 230-231; Harel 2014: 96-98; Ewing 2015: 371-372.
} 
is less costly and the resources that a continuous law requires may prevent the suffering of innocent persons if used elsewhere.

Therefore, it is unreasonable to assume that the reason against undeserved suffering always (or even almost always) supports a law that is continuous in the sense that is relevant to the Continuity Argument. Indeed, the overall conclusion may often be in favor of a law that imposes a sanction that does not accurately track blame (namely, an undeserved sanction). In such cases, the law may be justified, all-things-considered, although it is discontinuous in that it imposes sanctions that do not reflect accurately the degree to which the relevant people are blameworthy. For example, there is reason against requiring a person whose action harmed another unjustifiably to pay the entire cost of the harm if, as a result of this payment, this person would suffer more than she deserved to suffer. However, the same type of reason also requires such a payment if without it another person would suffer an undeserved harm. Thus, there is no reason to assume that the considerations against undeserved legal sanctions always support, at the end of the day, a law that tracks a continuous moral factor rather than a law that is discontinuous. Since the pertinent reasons - for and against legal continuity - are often the same type of reasons (for example, a reason against undeserved suffering), it seems that the tendency to prefer the reasons for, rather than against, legal continuity is at least partly due to a bias towards the short term as opposed the long term.

Moreover, the consideration against undeserved legal sanctions is not the only moral consideration. Therefore, even when this consideration supports a continuous law, it may be defeated by another consideration, for example, in favor of giving priority to the worse-off or maximizing well-being.

It may be retorted that there is nevertheless a more narrow consideration that is (almost) always decisive. The most common claims in this regard appeal to deontological constraints against intentional undeserved suffering, or, even more specifically, against undeserved punishment, or even just undeserved legal punishment. (Considerations relating to consequences, even those that focus on desert, are less often considered to be absolute or even almost absolute.) These suggestions are based on the common claim that considerations of desert are not symmetrical (at least or especially) when it comes to (intentional) punishment, 
and particularly legal punishment, namely, that the consideration against undeserved (criminal) punishment is much more important than the consideration in favor of preventing undeserved harm that is not in the form of (legal) punishment. ${ }^{39}$

Notice that these suggestions are very limited: they concern only intentional harm, or punishment, or legal punishment. Therefore, they do not support the Continuity Argument in its general form. They do not apply, for example, to laws that do not impose punishment in the relevant sense.

I believe, moreover, that even these limited suggestions are implausible. The version that refers to legal punishment is implausible since it is incompatible with the assumption that the law is merely a means and is therefore not a constitutive element of a foundational moral standard. The other versions are compatible with this assumption. But while there is a foundational reason against undeserved suffering, and thus a derivative reason against punishment, including legal punishment, that does not accurately reflect the degree to which the relevant person is blameworthy, it is unreasonable to hold that this reason is always, or even almost always, decisive. It is one thing to argue that something (such as desert) is valuable; it is a very different thing to argue that this value defeats every other value, or combinations of values, in every possible case, or even that this is almost always the case. The former claim is plausible; the latter is not. Indeed, even the suggestion that this reason if often decisive is far from obvious.

One argument against the claim that the reason against imposing undeserved (and indeed deserved) punishment is (almost) always decisive is based on the proposition that the force of

\footnotetext{
${ }^{39}$ Many believe that it is (almost) always wrong to use the criminal law against actions that are not wrong (see, for example, Husak 2008: 65-66, 76-77; Simester and von Hirsch 2011; Simester 2012: 483; Duff 2014: 218-221; du Bois-Pedain 2014; Danaher 2017: 77) or persons who are not blameworthy (see, for example, Alexander 2018: 532; Husak 2008: 82-83; Murphy 2016: 31; Moore 2017: 445).
} 
the pertinent reasons, for and against undeserved punishment, is a matter of degree. Therefore, the reasons in favor of undeserved punishment may be (relatively) strong, and the reasons against doing so may be (relatively) weak. When this is the case, it is plausible to conclude that the former defeat the latter. Moreover, this may be the case not only in very rare cases but more often.

Consider first the considerations in favor of punishment. The force of these considerations is a function of the degree to which the consequences of punishment are good, for example, in terms of maximizing well-being or promoting distributive or retributive justice, for instance, by preventing undeserved suffering. It may be thought that some of the goals that are associated with punishment or the criminal law - such as preventing wrongful harm and exacting retribution - could be promoted only by imposing (criminal) punishment on people who are blameworthy to the degree that justifies this punishment. However, the criminal law may promote moral goals that are ultimately related to wrongdoing and culpability even when it applies to people who are not blameworthy, for example, since there are often reasons to enact and enforce prohibitions whose ultimate goal is to prevent undeserved harm also with respect to actions that do not involve such harm or agents that are not blameworthy, due to the cost of distinguishing or separating various types of actions and agents. There are, in other words, reasons in favor of (enacting and enforcing) criminal prohibitions that are over-inclusive or not perfect in terms of desert alone.

In this way, the justification of undeserved (criminal) punishment is based also on goals that focus on wrongdoing and blame. And the force of the considerations in favor of such punishment depends on the degree to which it prevents wrongful harms or promote retribution, for instance. Thus, there may be strong considerations even in favor of punishing people who do not deserve the relevant punishment.

Indeed, many common criminal offenses appear to reflect this type of reasoning. This includes, generally, many prohibitions that are in the form of rules rather than principles. Consider, for 
instance, a common speed limit offense. ${ }^{40}$ The reasoning that underlies such an offense is presumably the combination of the following assumptions. First, driving is sometimes justified and sometimes not, depending, inter alia, on the extent to which it causes undeserved harm. In terms of risks: driving typically involves some risks, which are sometimes justified and sometimes not. Similarly, when driving is wrong, and the driver is blameworthy due to her action, the degree to which the action is wrong, or the driver blameworthy, depends (also) on the extent to which it causes undeserved harm. Second, the answers to the questions of whether the action is justified and to what degree is a wrongful action wrong or a blameworthy driver blameworthy, depend on many variables, including the capabilities of the driver, the condition of the car and the road, the weather and the reason for driving. Therefore, the speed that is justified is different in different cases. Similarly, the degree of wrongfulness and blame that are involved in driving at a certain speed are different in different cases. Third, the best way to prevent unjustified risks or to reduce the degree to which unjustified risks are wrong is often not a criminal prohibition on "unjustified risks" (a principle), or a punishment that accurately reflects wrongness or guilt (principles), but rather a prohibition that proscribes exceeding a specific speed limit (a rule), or a punishment that does not reflect degree of wrongness or blame accurately. Such rules are less accurate than the principles in terms of the moral status of the relevant actions: they are overinclusive in that their ultimate rationale is concerned with actions and are wrongful and harmful (to a certain degree) but they cover also other actions, which are permissible and harmless or less wrongful or less harmful than. However, these rules are often better than the alternative principles in terms of guiding drivers and the officials who enforce the law, since it is often

\footnotetext{
${ }^{40}$ This type of examples is discussed, in this context, by Duff 2002: 102; Alexander \& Ferzan 2009: $302-$ 304; Simester and von Hirsch 2011: 28; Edwards 2017; Cornford 2017.
} 
difficult to determine correctly what the relevant principle requires in specific circumstances. This consideration in favor of an over-inclusive criminal offense is forceful if such an offense prevents accidents more efficiently and thus prevents more suffering that is undeserved compared to a principle that track blame accurately.

Consider next the force of the considerations against punishment that involves undeserved harm. The force of this consideration is also a matter of degree. It depends, most notably, on the degree to which the excessive punishment is serious. Generally, the consideration against disproportionate punishment that is severe, such as a long prison sentence, is much stronger than the consideration against disproportionate punishment that is milder, such as a modest fine. (The same is true to condemnation to the degree to which it is not part of the punishment.)

Thus, it seems reasonable to conclude that criminal punishment is sometimes justified, allthings-considered, despite the fact that it involve undeserved harm. ${ }^{41}$ For example, when a speed limit offense prevents many accidents and thus saves many lives by imposing a relatively mild fine it seems to be justified overall even if it leads to punishment that does not reflect blame accurately..$^{42}$

The objection that there is a deontological constraint against undeserved punishment that is not a matter of degree and specifically not sensitive to the degree of punishment (and condemnation) - and that this consideration is nevertheless (almost) always decisive - is implausible. This is true more generally. For example, it does not seem wrong to break the finger

${ }^{41}$ Compare Schauer 1991; Alexander and Sherwin 2001; Alexander \& Ferzan 2018: 50.

${ }^{42}$ Compare Simester \& von Hirsch 2011: 251. Alexander \& Ferzan 2009: 295-306 argue that the criminal law should be generally composed of standards rather than rules, since rules are less accurate in the relevant respect. However, they acknowledge the costs that standards often involve and accept that, due to these costs, a rule is sometimes justified. 
of an innocent person when this is the only way to prevent a very serious injury to another innocent person. Since the harm involved in using a criminal law that carries relatively mild punishment (and condemnation), for example, a fine due to speeding, is often not more serious than a broken finger, it is implausible to assume that it is wrong to enact and enforce this law if this promotes an important goal such as preventing serious harm that is undeserved by preventing accidents.

Indeed, a more general argument against the claim that there is (almost) always a decisive reason against undeserved punishment is an analogy argument. The view that harming people is sometimes justified even when it is not deserved, mainly in order to prevent a more serious harm to innocent people (as in the broken finger case) is plausible and widely accepted (by both consequentialists and deontologists). Indeed, it is widely agreed that even serious harm to people that are completely innocent is sometimes justified, for example, diverting a trolley that would otherwise kill five persons to a track in which it would kill one. This common view is often reflected in the law, which often permits harming innocents. This includes the criminal law itself, which typically includes justificatory defenses, such as lesser evil, necessity and self-defense, that permit harm to innocents (innocent aggressors in the case of self-defense), when this is required in order to prevent a more serious harm to other innocents. Therefore, the question is whether the criminal law is so different that we should accept the opposite conclusion - that it is (almost) never justified to impose underserved harm, when this is done through the criminal law (as opposed to, inter alia, with the permission of the criminal law). I think that a positive answer is implausible. While the burdens imposed through the criminal law may be different from other burdens in various ways, it is not the case that it is often justified to harm innocents in other ways (mainly in order to prevent a more serious harm to other innocents) but (almost) never justified to do that through the criminal law.

Indeed, the morally significant differences between the criminal law and other ways in which individuals are harmed, including other forms of legal regulation, are often minor. This is the case, for example, regarding the difference between criminal offenses and "administrative offenses". Moreover, sometimes, the criminal law involves only a minor degree of harm (and condemnation) - for example, a parking violation that involves a small fine - while some non- 
criminal laws involve severe harm (and condemnation) - for example, preventive detention, expropriation, revoking a professional license or a sex offenders' registry. Therefore, a sharp distinction between criminal punishment and other burdens that are imposed by legal officials or other individuals is exaggerated.

The main objection to the analogy argument focuses on the differences between harming individuals through the criminal law and by other means. One objection is that criminal regulation is unique in that it involves condemnation or an intention to condemn. ${ }^{43}$ However, while it is reasonable to hold that undeserved condemnation is (often) bad or unjust, for example, since (when) it involves undeserved harm, the assumptions that only the criminal law involves condemnation, and that it involves it always, is false. Moreover, condemnation is a matter of degree and criminal regulation does not always involve serious condemnation (especially in the case of over-inclusive offenses). Finally, with regard to the version that focuses on the intention to condemn, it is doubtful whether intentions are morally significant in themselves with respect to the justification of actions (as opposed to agents). ${ }^{44}$

Another claim is that the it is (almost) never justified to impose undeserved harm by the criminal law since it is employed by public officials (or the state), although doing this by individuals who are not public officials is sometimes justified.$^{45}$ However, while there may be morally significant differences between individuals and public officials in terms of the justification of their actions, it is implausible to hold that they entail that harming innocents is often justified by individuals and (almost) never by public officials. Indeed, it is widely accepted that it is often

\footnotetext{
${ }^{43}$ See, for example, Husak 2009; Chiao 2013.

${ }^{44}$ See generally Scanlon 2008 and more specifically Enoch 2007; Kolber 2012; Chiao 2013.

${ }^{45}$ Bergelson 2018. Compare Husak forthcoming.
} 
justified to harm innocents even by public officials, for example, when the harm is due to administrative sanctions.

A more specific argument is that while harming innocents in the cases that are covered by justificatory defenses is necessary, it is not necessary in the case of criminal punishment, but rather "merely instrumental in achieving various consequentialist goals". ${ }^{46}$ Yet the (significance of the) difference between being "necessary" and being "instrumental" is unclear. And since the cases in which the criminal law is justified are those in which there is no better alternative, it seems that the criminal law is necessary in the sense that matters in the relevant respect.

Finally, a related suggestion is that the law allows individuals who are not public officials to harm innocents only in "emergencies", that is, when it is necessary to act immediately, whereas criminal punishment lacks this feature. ${ }^{47}$ However, while the need to act immediately is often important as an indication that the action is necessary, it does not seem to be important in itself (in terms of the justification of harming innocents). Therefore, this difference too does not seem to affect the conclusion that harming innocents by way of the criminal law is sometimes justified.

To conclude: while the consideration against undeserved punishment is sometimes decisive, the claim that this consideration is (almost) always decisive is implausible. Consequently, even in the context of the criminal law there is no reason to assume, without conducting extensive moral and empirical inquiries, that the law (at a certain time and place) should be usually continuous (or that it should be more continuous that it actually is).

\footnotetext{
${ }^{46}$ Bergelson 2018.

${ }^{47}$ Bergelson 2018.
} 


\section{An Example: Partial Defenses}

The controversy regarding partial defenses in the criminal law illustrates several points regarding the Continuity Argument and the doubts concerning this argument. This is because some of the arguments for and against partial defenses focus on the degree to which morality is continuous in various respects and on the extent to which the law should be continuous as well in order to reflect the relevant moral continuity. I therefore conclude by considering the lessons of the above discussion with respect to several aspects of the controversy about partial defenses.

Let us begin with justificatory defenses, namely, defenses that focus on the moral status of the relevant actions, namely, exempt actions that are morally permissible. Consider first the flowing argument for complete justificatory defenses:

1. The criminal law should apply only to actions that cross a certain, minimal, threshold, of wrongfulness (this is thus a necessary but not a sufficient condition). ${ }^{48}$

2. Some of the legal rules that reflect premise 1 (that the criminal law should not apply to certain actions because they are not wrong, or are not wrong enough) should take the form of defenses.

3. Some of the above defenses should provide a complete exemption from criminal liability (and accordingly should be called "complete justificatory defenses").

Now consider a similar argument for partial justificatory defenses ${ }^{49}$ :

${ }^{48}$ This claim goes beyond the very common claim that the criminal law should not apply to actions that are morally permissible (see Section 3 for the latter claim).

${ }^{49}$ For arguments in this spirit, see Husak 1998; Segev 2010; Kolber 2016: 870-872. These arguments are different from the arguments that I have in mind in several respects. For example, Husak claims that if a certain factor justifies a complete defense, then if this factor is present to a lesser degree, it justifies a partial defense. However, he refers to factors that are not important in themselves to the criminal law 
1. When the criminal law should apply to wrongful actions, the severity of the punishment should depend, inter alia, on the degree to which the relevant action is wrong: other things being equal, an action that is less wrong, should be subject to a lesser punishment.

2. Some of the legal rules that reflect premise 1 (that the criminal law should impose lesser punishment in response to certain actions, compared to others, because the former are less wrong) should take the form of defenses.

3. Some of the above defenses should provide a partial exemption from criminal liability (and accordingly should be called "partial justificatory defenses").

The propositions that comprise these arguments are plausible, it seems to me, but only given the following qualifications. First, the common assumption (variations of which are endorsed by several of the premises in the above arguments) that the criminal law should take account of the moral status of actions - including whether they are wrong or not, and to what degree - is plausible both if the moral status of actions matters for the criminal law in itself and also if it matters in this respect only since, and to the degree to which, it affects other factors that are morally significant in themselves, such as the effects of the law in terms of preventing the bad

but rather, at most, only as proxies, for instance, age. In this sense, the above claim is inaccurate. It is implausible to hold that if a young age is a complete defense then an age that is less young should be a partial defense (as Husak suggests). For age matters, for the criminal law, only if, and to the degree to which, it affects another factor that does matter in itself, such as the degree to which the relevant person is blameworthy. And age does not always have this effect. For example, the difference between a person who is 50 years old and a person who is 40 years old is often not significant in this regard. The correct thesis is accordingly merely the more trivial claim that if, for example, the moral status of agents matters for the criminal law, then it should matter not only if a person is not blameworthy at all but also to the degree to which a person is blameworthy. Kolber suggests that the punishment in the case of partial defenses should reflect only the degree to which the action exceeds the minimal threshold of wrongness. But I do not think that the relevant considerations support this suggestion. 
consequences of actions or desert. ${ }^{50}$ Second, assuming that the moral status of actions matters for the criminal law, the reason against using the criminal law against actions that are not wrong, or in a way that does not properly reflect the degree to which actions are wrong, is not necessarily decisive. ${ }^{51}$ Third, the justification of every legal rule depends on its overall consequences. Therefore, both complete and partial justificatory defenses are justified in some factual settings but not in others. This means also that, sometimes, complete justificatory defenses are appropriate (since their overall consequences are optimal) and partial justificatory defenses are inappropriate (since their overall consequences are not optimal). But the opposite is equally true in other cases. ${ }^{52}$

These qualifications imply that the claims that the criminal law should not apply to actions that are not wrong, or are not wrong enough, are correct sometimes but not always. However, this does not imply that legal rules that exempt every action that is not wrong from the scope of the criminal law, or that require that the criminal law should be used in a way that properly reflects the degree to which the relevant actions are wrong, are necessarily out of place. For the overall consequences of such legal rules may be optimal even if the reasons against undeserved punishments are not always decisive. This may be the case, for example, if legal officials tend to use the criminal law too much, especially with regard to actions that are not wrong, or not wrong enough, ${ }^{53}$ and legal rules that instruct them never to use the criminal law against actions that are

\footnotetext{
${ }^{50}$ See Section 2.

${ }^{51}$ See Section 3.

${ }^{52}$ In this regard, I think that the connection between complete and partial justificatory defenses is weaker than what Husak 1998 seems to suggest.

${ }^{53}$ See Husak 2008.
} 
not wrong to the required degree will bring the use of the criminal law against such actions closer to the appropriate level. In order to accommodate this point I assume here that legal rules that accurately reflect the degree to which the relevant actions are wrong are optimal in terms of their overall consequences. Fourth, whether a conclusion that the criminal law should not apply to certain actions should take the form of a legal defense, or other ways of excluding actions from the scope of the criminal law, such as excluding the relevant actions from the scope of criminal offenses to begin with, or relying on the discretion of the officials that enforce the law, also depends on the answer to the question of which alternative would bring about the best overall consequences. In order to sidestep this debate too, I assume, for the sake of the discussion, that defenses are the best alternative in this regard. Finally, whether or not such a defense should be called a "partial justificatory defense", or a "complete justificatory defense", or something else, also depends on the overall consequences of doing so.

Subject to these qualifications, it seems to me that the above arguments for complete and partial justificatory defenses are compelling. Since the conclusions of these arguments are conditional - they entail the relevant defenses only if their overall consequences are optimal, objections that focus on these consequences are beside the point. Some other objections to partial defenses are worth considering in the context of the Continuity Argument, however.

The first objection to partial justificatory defenses is that the idea of partial justificatory defenses involves a contradiction, since "justifications... seem to be indivisible and by nature binary: conduct is either justified and permissible or it is not". ${ }^{54}$ This objection should be

${ }^{54}$ Eldar and Laist 2014: 161. Compare: Uniacke 1994: 13-14; Dsouza 2017: 102. 
dismissed quickly55: even assuming, for the sake of the argument, that the term "partial justification" involves a contradiction, the above argument in favor of the relevant type of a legal rule is not contradictory, and a legal defense of the relevant type is not contradictory. Therefore, the objection is merely terminological: it is properly addressed simply by using a different term in order to describe the relevant legal rule - a term of art, if necessary. ${ }^{56}$ Indeed, "when our language doesn't adequately express our thoughts, it's better to add expressions to our language than to abandon our thoughts". 57

(However, it is worth noting, in passing, that the assumption that the term "partial justification" involves a contradiction is unwarranted. First, even if the standard meaning of the term "justification" is binary, the term "partial justification" is a different term. Moreover, the latter is a term of art and there is no reason to assume that those who use it are simply confused. Actually, those who use this term may acknowledge that it is odd given the common meaning of the relevant words. They nevertheless use it since it has various advantages, most importantly, as I emphasize below, since it highlights the important common denominator of (the arguments for) complete and partial justificatory.)

55 Indeed, it seems that Eldar and Laist themselves do not consider this point itself as an objection. They acknowledge that "one may still wish to find some terminological use for partial justification. In this case, it will not do to charge one with incoherence or unintelligibility. Indeed, language can be stretched to fit the term" (Eldar and Laist 2014: 163).

${ }^{56}$ Recall that if the objection is concerned with the consequences of the using certain terms, then it is compatible with the proposed argument for partial justificatory defenses since this argument is conditional: it applies only when such a defense have optimal consequences on balance in this respect too.

${ }^{57}$ Seinhababu 2018: 3134. 
The next, and more important, objection is that partial justificatory defenses do not have enough in common with complete justificatory defenses and therefore classifying these defenses together is misleading. ${ }^{58}$ Some claim, for example, that complete justificatory defenses have two features that partial justificatory defenses lack. One is that complete justificatory defenses guide prospective agents since they apply, or should apply, only to actions that are morally permissible, whereas partial justificatory defenses, which (should) apply to actions that are unjustified, do not provide the same type of guidance. ${ }^{59}$ The other alleged difference is that it is morally wrong, and should be legally forbidden, to prevent actions that are covered by complete justificatory defenses, while this is not the case regarding actions that are covered by partial justificatory defenses. $^{60}$

I think, however, that complete and partial justificatory defenses have enough in common to justify the classification of both types of defenses as justificatory defenses. Specifically, these categories have two important characteristics in common: both focus on the moral status of actions $^{61}$; and both apply to some actions that are wrong. The latter, it is important to notice, is true also regarding complete justificatory defenses since some actions are wrong only to a degree that does not justify the use of the criminal law (at all). Therefore, the assumption that complete justificatory defenses (should) apply only to actions that are not wrong, and in this way provide proper guidance to prospective agents, is false.

${ }^{58}$ Eldar and Laist 2014: 163.

${ }^{59}$ Eldar and Laist 2014: 159, 170.

${ }^{60}$ Eldar and Laist 2014: 159, 161.

${ }^{61}$ This is significant even if, as I believe, the moral status of actions matters only derivatively for the criminal law. 
The other assumption - that actions that are covered by complete justificatory defenses should not be resisted - is also mistaken. The moral status of the action of one person does not determine, in itself, the moral status of the actions of others, including those that respond, in various ways, to the first action. This is the case not only if I am right that the moral status of actions, as opposed to the moral status of their consequences and of the agents who perform them, is not in itself important to others at all. ${ }^{62}$ For even if the moral status of the action of one person affects, in itself, the moral status of the action of another, this factor is not always decisive; it may be defeated by other relevant factors that pull in the opposite direction. For example, if the consequences of the first action and of an action that interferes with it are different, their moral status is accordingly different in this respect. (The moral status of the relevant actions may be different also if there are agent-relative reasons and if the moral status of actions depends on the beliefs of the agents. ${ }^{63}$ )

This brings us to the final and most interesting point with regard to the Continuity Argument: the above objections to partial justificatory defenses are more plausible if they assume, as they seem to do, that the common view that there is an important difference between actions that are right and actions that are wrong, even if this difference is due to a difference that is small, for instance, in the consequences of these actions. Therefore, if this view is misguided, and morality should take a more scalar form, ${ }^{64}$ the difference between complete and partial justificatory defenses is not significant and indeed appears to be trivial. For both types of defenses apply to actions in light of their moral status, and more specifically, apply to actions since they are not

\footnotetext{
${ }^{62}$ See Section 2.

${ }^{63}$ See Section 2.

${ }^{64}$ See Section 2.
} 
wrong to a degree that justifies the use of the criminal law (or its use in a certain way). To be sure, complete justificatory defenses, unlike partial justificatory defenses, apply also to some actions that are not wrong at all. But, first, even complete justificatory defenses apply also to actions that are wrong. And, more importantly, the difference between actions that are not wrong (at all) and actions that are wrong only in the sense that they are not perfect, is sometimes trivial. If this is indeed the case, there does not seem to be much point in distinguishing between complete and partial justificatory defenses at all. ${ }^{65}$

A similar analysis applies to excusatory defenses, which focus on the moral status of agents rather than that of actions, given the common assumption that relates the moral status of agents and actions. ${ }^{66}$ The claim that there should be partial excusatory defenses is less controversial than the suggestion that there should be partial justificatory defenses. However, if the moral status of actions and of agents are related in the way that many assume, namely, if the moral status of agents depends (only or also) on the moral status of their actions, there is no difference between justificatory and excusatory defenses in this respect.

\section{Conclusion}

While the Continuity Argument is attractive, there are two main doubts with regard to it. One is that the first premise is incompatible with the common view that the overall moral status of

65 In this respect, it may be true that "there is no meaning to partial justification under consequentialism, apart from saying that within the calculus, some good consequences of the act were weighed against the bad ones before the balance was found to be unfavorable, which can be said of most bad deeds" (Eldar and Laist 2014: 162). However, this does not entail that there is no room for partial justificatory defenses, as this observation applies also to complete justificatory defenses.

${ }^{66}$ See Section 2. 
actions is discontinuous, since there is a dramatic difference between actions that are right (obligatory or permissible) and actions that are wrong (and between agents that are praiseworthy and agents that are blameworthy to the degree to which the moral status of agents depends on their actions). I believe, however, that this view should be rejected and therefore that the first premise of the Continuity Argument is correct in this regard. The second doubt concerns the scope of the second premise of the argument: as there are often reasons against legal continuity, and not only in favor of legal continuity, and the applicability and force of both types of reasons depend, inter alia, on contingent facts, we lack the evidence to determine the degree to which the law, at a certain place and time, should be continuous (and specifically that it should be often continuous).

\section{References}

Alexander, Larry. 2000. "Deontology at the Threshold". San Diego Law Review 37: 893-912.

Alexander, Larry. 2008. "Scalar Properties, Binary Judgments". Journal of Applied Philosophy 25: 85-104.

Alexander, Larry and Kimberly Kessler Ferzan, 2018. Reflections on Crime and Culpability: Problems and Puzzles (Cambridge: Cambridge University Press).

Bergelson, Vera. 2018. “Does Fault Matters?” Criminal Law \& Philosophy 12: 375-392.

Brink, David 2019. "The Nature and Significance of Culpability". Criminal Law and Philosophy 13: 347-373.

Chiao, Vincent. 2013. "Punishment and Permissibility in the Criminal Law". Law \& Philosophy 32: 729-765.

Constantinescu, Cristian. 2014. Moral Vagueness: A Dilemma for Non-Naturalism. In Russ Shafer Landau (ed.), Oxford Studies in Metaethics (Oxford: Oxford University Press), pp. 152-185.

Danaher, John. 2017. "Robotic Rape and Robotic Child Sexual Abuse: Should They be Criminalised?" Criminal Law \& Philosophy 11: 71-95.

Dsouza, Mark. 2017. Rationale-Based Defences in Criminal Law (Oxford: Hart).

du Bois-Pedain, Antje. 2014. "The Wrongfulness Constraint in Criminalisation". Criminal Law \& Philosophy 8: 149-169. 
Duff, R. A. 2014. "Towards a Modest Legal Moralism". Criminal Law \& Philosophy 8: 217-235.

Eklund, Matti, 2011. "Being Metaphysically Unsettled: Barnes and Williams on Metaphysical Indeterminacy and Vagueness". In Karen Bennet and Dean W. Zimmerman (eds.) Oxford Studies in Metaphysics Vol. 6 (Oxford: Oxford University Press) pp. 149-172.

Eldar, Shachar, and Laist, Elkana. 2014. "The Misguided Concept of Partial Justification". Legal Theory 20: 157-185.

Hooker, Brad. 200. Ideal Code, Real World (Oxford: Clarendon Press).

Hooker, Brad. 2006. "Right, Wrong and Rule Consequentialism". In H. West (ed.), The Blackwell Guide to Mill's Utilitarianism (Hoboken: Wiley-Blackwell) pp. 233-248.

Husak, Douglas. 1998. "Partial Defenses".

Husak, Douglas. 2008. Overcriminalization: The Limits of the Criminal Law (Oxford: Oxford University Press).

Husak, Douglas. Forthcoming. "Wrongs, Crimes, and Criminalization", Criminal Law \& Philosophy. Kagan, Shelly. 1984. “Does Consequentialism Demand Too Much? Recent Work on the Limits of Obligation". Philosophy \& Public Affairs 13: 239-254.

Kagan, Shelly. 1989. The Limits of Morality (Oxford: Clarendon Press).

Katz, Leo. Why the Law is so Perverse (Chicago: University of Chicago Press, 2011).

Kolber, Adam. 2012. "Unintentional Punishment”. Legal Theory 18: 1-29.

Kolber, Adam. 2014. "Smooth and Bumpy Laws". California Law Review 102: 665-690.

Kolber, Adam. 2016. "The Bumpiness of Criminal Law". Alabama Law Review 67: 855-886.

Kolber, Adam. 2016A. "Smoothing Vague Laws". In Geert Keil and Ralf Poscher (eds.), Vagueness and Law: Philosophical and Legal Perspectives (New York: Oxford University Press), pp. 275295.

Lawlor, Rob. 2009. "The Rejection of Scalar Consequentialism". Utilitas 21: 100-116.

Lang, Gerald. 2013. "Should Utilitarianism Be Scalar?" Utilitas 25: 80-95.

McElwee, Brian. 2010. "The Rights and Wrongs of Consequentialism". Philosophical Studies 151: 393-412.

Moore, Michael S. 2017. “Legal Moralism Revisited”. San Diego Law Review 54: 441-464. 
Murphy, Jeffrie G. 2017. “Last Words on Retribution". In Jonathan Jacobs and Jonathan Jackson (eds.), The Routledge Handbook of Criminal Justice Ethics (New-York: Routledge), pp. 28-41. Murphy, Liam. 2000. Moral Demand in Nonideal Theory (New-York: Oxford University Press). Norcross, Alastair. 1997. "Good and Bad Actions". The Philosophical Review 106: 1-34.

Norcross, Alastair. 2005. "Contextualism for consequentialists". Acta Analytica 20: 80-90.

Norcross, Alastair. 2006. "The Scalar Approach to Utilitarianism". In H. West (ed.), The Blackwell Guide to Mill's Utilitarianism (Malden: Blackwell), pp. 217-232.

Norcross, Alastair. 2006A. "Reasons Without Demands: Rethinking Rightness". In J. L. Dreier (ed.), Contemporary Debates in Moral Theory (Malden: Blackwell), pp. 6-38.

Scanlon, T. M. 2008. Moral Dimensions: Permissibility, Meaning, Blame (Cambridge: Harvard University Press).

Scheffler, Samuel. 1982. The Rejection of Consequentialism (Oxford: Oxford University Press).

Schoenfield, Miriam. 2016. "Moral Vagueness is Ontic Vagueness". Ethics 126: 257-282.

Segev, Re'em. 2010. "Sub-Optimal Justification and Justificatory Defense." Criminal Law and Philosophy 4: 57-76.

Segev, Re'em. 2012. "Justification Under Uncertainty". Law and Philosophy 31: 523-563.

Segev, Re'em. 2017. "Should Law Track Morality?" Criminal Justice Ethics 36: 205-223.

Segev, Re'em. Draft 1. "Actions, Agents, and Consequences".

Segev, Re'em. Draft 2. "Normative Innocence".

Seinhababu, Neil. 2018. "Scalar Consequentialism the Right Way". Philosophical Studies 175: 3131-3144.

Shafer-Landau, Russ. 1995. "Vagueness, Borderline Cases and Moral Realism". American Philosophical Quarterly 32: 83-96.

Simester, A. P. 2012. "Enforcing Morality". In Andrei Marmor (ed.), The Routledge Companion to Philosophy of Law (New-York: Routledge), pp. 482-494.

Simester, Andrew and Andreas von Hirsch, 2011. Crimes, Harms, and Wrongs: On the Principles of Criminalisation (Oxford: Hart).

Singer, Peter. 1993. Practical Ethics (2 ${ }^{\text {nd }}$ ed., Cambridge: Cambridge University Press). 
Slote, Michael and Pettit, Philip. 1984. "Satisfying Consequentialism". Proceedings of the Aristotelian Society 58: 139-176.

Temkin, Larry. 1993. Inequality. (New York: Oxford University Press).

Tobia, Kevin. 2017. "A Defense of Scalar Consequentialism". American Philosophical Quarterly 54: 283-294.

Unger, Peter. 1996. Living High and Letting Die: Our Illusion of Innocence (New-York: Oxford University Press).

Uniacke, Suzanne. 1994. Permissible Killing: The Self-Defense Justification of Homicide (Cambridge: Cambridge University Press). 